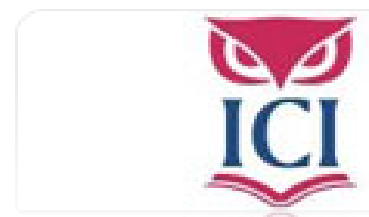

IUS. Revista del Instituto de Ciencias Jurídicas de Puebla A.C.

ISSN: 1870-2147

revista.ius@hotmail.com

Instituto de Ciencias Jurídicas de Puebla A. C.

México

Álvarez Álvarez, Leonardo

La función de la constitución democrática y los institutos jurídico-normativos para su tutela IUS. Revista del Instituto de Ciencias Jurídicas de Puebla A.C., núm. 21, 2008, pp. 43-64 Instituto de Ciencias Jurídicas de Puebla A. C.

Puebla, México 


\title{
LA FUNCIÓN DE LA CONSTITUCIÓN DEMOCRÁTICA Y LOS INSTITUTOS JURÍDICO-NORMATIVOS PARA SU TUTELA
}

\author{
Leonardo Álvarez Álvarez ${ }^{*}$
}

\begin{abstract}
SUMARIO
1. La función normativa de la Constitución democrática

y el instrumentario jurídico para su protección 1.1. Como presupuesto para la definición de los institutos destinados a su tutela

1.2. La defensa de la Constitución 1.3. La defensa del Estado

2. La función normativa de la Constitución democrática al servicio de la eficacia del ordenamiento

2.1. La función de la Constitución democrática y la eficacia del ordenamiento jurídico 2.2. La intangibilidad del principio democrático y la función normativa de la Constitución democrática 2.3. El principio de no identificación del Estado y su función normativa de la Constitución democrática
\end{abstract}

\section{RESUMEN}

Hace ya tiempo que la teoría general del derecho, la moderna teoría del Estado y la ciencia del derecho constitucional se han ocupado del mejor modo de proteger al Estado. En la actualidad, el tratamiento de tal cuestión parecía estar ya superada. Sin embargo, los trágicos atentados terroristas perpetrados en Nueva York el 11 de septiembre de 2001 con arreglo a procedimientos desconocidos hasta entonces, han exigido el replanteamiento de las técnicas de tutela de los estados democráticos. La posibilidad de que los

\section{ABSTRACT}

For long time Legal Theory, modern Theory of Government and Constitutional Law have dealt the best way to protect Government. Nowadays the treatment of this question seemed already superseded. Nevertheless, the tragic terrorist attacks of 9/11 in New York - according to procedures completely unknown until then- have demanded for a reconsideration of the protective tactics employed in democratic States. The possibility that terrorists could act as suicides has revived the controversy

* Doctor en derecho y profesor de derecho constitucional de la Universidad de Oviedo, España. 
terroristas pudiesen actuar como suicidas ha hecho resurgir de nuevo el debate sobre los mecanismos necesarios para proteger las democracias contemporáneas. El presente trabajo pretende exponer las premisas de cómo compatibilizar la defensa contra el terrorismo y la defensa de la democracia. of which instruments would be necessary to protect contemporary democracies. This paper is directed to expound some premises of how to make compatible protection against terrorism and protection of the democracy.

La historia del pensamiento jurídico se ha vinculado en buena parte de las ocasiones al mejor modo de garantizar la eficacia de las normas reguladoras del comportamiento humano, ya hayan sido concebidas aquéllas como integrantes de un sistema propiamente jurídico, o conformadoras de otros sistemas sociales. ${ }^{1}$ El particular modo de proceder a la tutela de un orden normativo tal ha ido parejo a la mayor o menor complejidad de las sociedades y también, en los ordenamientos jurídicos modernos, a las diversas formas de Estado. Y así, tanto la forma de Estado liberal como la democrática han desarrollado ya institutos normativos bien perfilados destinados a la preservación y a la eficacia del ordenamiento jurídico. Sin embargo, el modo de proteger el Estado, y muy particularmente el Estado democrático de derecho, que parecía ser ya una cuestión superada, ha adquirido una relevancia de primer orden en la actualidad. Los nuevos modos de terrorismo -islámico- ${ }^{2}$ adoptados en la actualidad, desconocidos hasta entonces, y reflejados con una intensidad y con unas consecuencias sin par el 11 de septiembre del año 2001 en Nueva York, han requerido de los estados -y también de la ciencia del derecho constitucional- el replanteamiento de los términos sobre cómo defenderse frente a las nuevas amenazas. ${ }^{3}$

${ }^{1}$ Cfr. Al respecto 0. von Gierke, Das deutsche Genossenschaftsrecht, t. 11, Ed. Akad. Dr.- u. Verlagsanst, Graz, 1954, pp. 280ss.

${ }^{2}$ Véase B. Grzeszick, "Staat und Terrorismus: Eine staatstheoretische Überlegung in praktischer Absicht”, en J. Isensee (Edit.), Der Terror, der Staat und das Recht, Ed. Duncker Ct Humblot, Berlin, 2004, pp. $55 s s$.

${ }^{3}$ Véase E. Werthebach, "Deutsche Sicherheitsstrukturen im 21. Jahnhundert", Aus Politik und Zeitgeschichte, No. 44, 2004, pp. 5ss, así como también C. Gusy, "Geheimdienstliche Aufklärung und Grundrechtsschutz", Idem., pp. 14ss. Normativas tales como la Ley de Seguridad Aérea adoptadas por el ordenamiento alemán - pionero en la doctrina de la defensa del Estado democrático de derecho-, que autorizaba al Estado a derribar aeronaves en el caso de que se encontrasen dirigidas por suicidas en contra de la población civil sólo pueden comprenderse en el contexto de los atentados del 11 de septiembre de 2001 en Nueva York, C. Tomuschat, "Der 11. September 2001 und seine rechtlichen Konsequenzen”, Europäische Grundrechte-Zeitschrift, 2001, pp. 535ss. También W. Mitsch, Luftsicherheitsgesetz - Die Antwort des Rechts auf den 11 September 2001, Juristische Rundschau, 2005, 276ss. La constitucionalidad de esta ley ha tenido la ocasión de ser enjuiciada por la BverfGE, 115, 118, de 15 de febrero de 2006. 
Pero el cambio operado en el panorama global democrático se ha visto también transido de una creciente multiculturalidad presente en los estados actuales, fundamentalmente islámica, que ha requerido de aquéllos también la búsqueda de fórmulas destinadas a interiorizar las culturas y valores de otras civilizaciones en el seno de los sistemas jurídicos. ${ }^{4} \mathrm{La}$ cuestión de la manifestación perfectamente democrática de los símbolos religiosos de aquellas culturas en las sociedades actuales ha venido a poner en crisis uno de los pilares sobre los que se edificaría la moderna teoría del Estado: la idea del Estado-nación culturalmente homogéneo. Ofrecer una solución teórico-jurídica adecuada para la incardinación estatal de tal multiculturalidad, se presenta como un reto insoslayable para los estados contemporáneos si, imposibilitados ya para fundamentar su propia soberanía a partir de un sustrato sociocultural homogéneo y autónomo, desean mantener su eficacia y su autopreservación como órdenes reguladores del uso de la fuerza. Ofrecer fórmulas para la defensa de la Constitución democrática, tanto frente a actos ilícitos, como a expectativas perfectamente democráticas es el gran reto actual de los estados. Ofrecer las bases dogmáticas para la adecuada inserción de las diferentes expectativas culturales, religiosas en los estados democráticos es el objeto de este trabajo.

\section{La función normativa de la Constitución democrática y el instrumentario JURÍDICO PARA SU PROTECCIÓN}

\subsection{Como PRESUPUeSto PARA la definición DE LOS INSTITUTOS DESTINADOS A SU TUTELA}

La admisión de institutos jurídico-normativos destinados a responder frente a la infracción, muy particularmente, de las normas constitucionales aparece como una exigencia teórica inexcusable allí donde la Constitución se conciba, ante todo, como norma jurídica -independientemente

\footnotetext{
${ }^{4}$ Eso es lo que ya se ha planteado en el seno del ordenamiento alemán en el caso del crucifijo, resuelto por el BverfGE, 93, 1, el de 16 de mayo de 1995, o la cuestión de la portación del velo musulmán en las escuelas, también reflejada en la jurisprudencia constitucional, en la BverfGE, 108, 282, de 24 de septiembre de 2003. Véase sobre estas cuestiones en la doctrina A. Thorsten, Islam in der Schule. Rechtliche Wirkungen der Religionsfreiheit und der Gewissensfreiheit sowie des Staatskirchenrechts im öffentlichen Schulwesen, Duncker \& Humblot, Berlin, 2003, pp. 16ss. También J. 1sensee, "Private islamische Bekenntnisschulen: zur Ausnahme vom Verfassungsprinzip der für alle gemeinsamen Grundschule", en Stefan Muckel (Edit.), Kirche und Religion im sozialen Rechtsstaat. Festschrift für Wolfgang Rüfner zum 70. Geburtstag, Duncker \& Humblot, Berlin, 2003, pp. 355ss; U. Sackofsky, "Die Kopftuch-Entscheidung - von der religiösen zur föderalen Vielfalt”, Neue Juristische Wochenschrift, 2003, pp. 3297ss.
} 
del valor jerárquico que ella misma se hubiese autoatribuido ${ }^{5}$ e incluso de la estructuración por ella elegida de las funciones de creación y aplicación de normas-. Aquella Constitución que pudiese ser lícitamente infringida no podría reclamar para sí siquiera la calificación de norma jurídica. ${ }^{6}$ Sin embargo, dejando a un lado esta elemental cuestión, la función normativa que haya pretendido ejercer la Constitución puede requerir dogmáticamente -a fin de poder desempeñarla eficazmente- la previsión normativa de determinados institutos y no de otros. Y así, del mismo modo que el instrumentario jurídico-normativo destinado a garantizar la eficacia de una Constitución que se haya autocomprendido como norma jerárquicamente suprema no puede ser el mismo que el que pretenda tutelar una Constitución que se equipare en rango a la ley -lo que ha sucedido fundamentalmente a lo largo del constitucionalismo europeo del siglo XIX, ${ }^{7}$ la norma constitucional que estructure, en concreto, las funciones de creación y aplicación de normas con arreglo al principio democrático ha de ser objeto también de una tutela jurídico-normativa específicamente propia. ${ }^{8}$

La Constitución democrática, con su función consistente en adecuar en la mayor medida posible el contenido de la voluntad de las normas jurídicas -también de la Constitución- y el de la voluntad de la de los sujetos a ellas, pretende la canalización de las diferentes expectativas políticas en

\footnotetext{
${ }^{5}$ Sobre los mecanismos de protección de la Constitución frente a su infracción, incluso en los casos en los que aquélla se ha equiparado en rango a la ley, véase E.-R. Huber, Deustche Verfassungsgeschichte. Seit 1789, Vol. 11 (Bismark und das Reich), Ed. Kohlhammer, Stuttgart, 1988, pp. 1007ss. También al respecto C. Gusy, Weimar - Die wehrlose Republik?, Ed. J.C. B. Mohr, Tübinga, 1991, pp. 152ss y E. Huber, Deutsche Verfassungssgeschichte. Seit 1789, t. v1, Ed. Kohlhammer, Stuttgart, 1981, pp. 150-151.

${ }^{6}$ Algo que ha sucedido en el constitucionalismo hispánico, donde la Constitución se concibió en ocasiones como un mero documento dotado de valor programático-político, que fue el resultado de un pacto entre las diferentes fuerzas políticas. Acerca de la inexistencia de un concepto de Constitución como norma suprema en la historia constitucional española, véase J. Varela Suanzes, "La doctrina de la Constitución histórica: de Jovellanos a las Cortes de 1845”, Revista de Derecho Político, No. 39, 1994, pp. 54ss., 1. Fernández Sarasola, Poder y libertad: los orígenes de la responsabilidad del Ejecutivo en España (1808-1823), Ed. Centro de Estudios Políticos y Constitucionales, Madrid, 2001, p. 303 y del mismo autor, "Valor y supremacía de la Constitución de 1812", en R. Sánchez Ferriz y M. García Pechuan, La enseñanza de las ideas constitucionales en España e Iberoamérica, Ed. Ene, Valencia, 2001, p. 197. Incluso en el seno de la vigente Constitución española de 1978 no han faltado quienes hayan pretendido mantener esta concepción de Constitución, degradando su concepción inequívocamente normativa, lo que se deduce de su Art. 9.1. Acerca de aquella manera de concebir la Constitución española, véase M. Herrero de Miñón, “La Constitución como pacto", Revista de Derecho Politico, No. 44, 1978, pp. 20-21.

${ }^{7}$ Cfr. R. Wahl, "Der Vorrang der Verfassung”, Der Staat, No. 20, 1981, p. 498.

${ }^{8}$ Véase H. Kelsen, Verteidigung der Demokratie, Aufsätze zur Demokratietheorie, Ed. Mohr, Siebeck, 2006, p. 229ss.
} 
el seno del sistema jurídico con arreglo a un procedimiento plural e igual. ${ }^{9}$ Esta función no fue reconocida, sin embargo, en el seno del Estado liberal precedente históricamente a aquél -vinculado más a los presupuestos del principio de estado de derecho-, que sólo se garantizó la participación en el seno del Estado a aquellos que compartieron los presupuestos ideológicos del liberalismo. Esto, que se llevó a cabo fundamentalmente a través del instituto del sufragio censitario, hizo que el cambio de las normas tuviese que llevarse a cabo, no mediante la canalización de las expectativas en el interior del ordenamiento jurídico -como sí permite, por el contrario el principio democrático-, sino al margen del mismo, es decir, con una ruptura extra ordinem. ${ }^{10}$

La posibilidad de que las diferentes expectativas puedan ser canalizadas lícitamente a través del sistema jurídico -que permite la función de la Constitución democrática - ha contribuido en buena medida a garantizar la estabilidad del sistema jurídico al habilitar que aquéllas puedan desplegarse adecuadamente dentro de sus confines, no viéndose así avocadas a buscar su implantación a través de la infracción de las normas del sistema jurídico, exigida por la estructuración de la creación normativa propia del Estado liberal. Sin embargo, este beneficio que genera la función de la Constitución democrática para la estabilidad del ordenamiento ha generado, a la óptica de un nada despreciable sector doctrinal, otro relevante problema: lo que se ha denominado la paradoja de la democracia. ${ }^{11}$ Esta paradoja consistiría supuestamente en que la función normativa que trata de ejercer la Constitución democrática acaba permitiendo la interiorización en el ordenamiento jurídico incluso de aquellas expectativas que tratan de abolirlo. De esta forma, la Constitución democrática, si bien en teoría articulada con la función de garantizar la estabilidad del ordenamiento jurídico, acabaría dotando, de manera contradictoria con sus propios presupuestos, licitud a los esfuerzos que tratan de suprimirlo. ${ }^{12}$

\footnotetext{
${ }^{9}$ Véase H. Kelsen, Vom Wesen und Wert der Demokratie, Ed. Sciencia, Aalen, 1963, p. 20.

${ }^{10}$ Véase sobre ello E. Kaufmann, "Die Grenzen des Verfassungsmäßigen Verhantens nach den Bonner Grundgesetz, insbesondere: was ist unter einer freiheitlichen demmokratischen Grundordnung zu verstehen? Festvortrag aus dem 39. deutschen Juristentag 1951”, en E. Denninger, Freiheitliche Demokratische Grundordnung, t. 1, Materialen zum Staatsverständnis und zur Verfassungswirklichkeit in der Bundesrepublik, Ed. Suhrkamp, Francfort, 1977, pp. 97-98.

${ }^{11}$ Véase al respecto G.-P. Boventer, Grenzen der Politischer Freiheit in demokratischer Staat. Das Konzept der Streitbaren Demokratie in einem Internationalem Vergleich, Ed. Duncker \& Humblot, Berlin, 1985, pp. 16ss.

${ }^{12}$ Cfr. C. Holmes, "Verfassungsförmige Vorentscheidungen und das Paradox der Demokratie", en U. Preuss (Edit.), Zum Begriff der Verfassung, Ed. Fischer, Frankfurt, 1994, p. 133ss.
} 
En ello consiste la supuesta paradoja democrática, un argumento que ha servido como punto de partida para la construcción de una muy determinada teoría de la defensa de la democracia, en definitiva, de un instrumentario jurídico-normativo consustancial a la garantía de la función de la Constitución democrática. ${ }^{13}$ Esta teoría de defensa de la democracia se ha encontrado orientada a negar libertad a los enemigos de la libertad, conforme a las exigencias que ya habían sido reflejadas en los albores del constitucionalismo europeo. ${ }^{14}$

Sin embargo, como se tratará de analizar seguidamente, esta teoría -difundida principalmente en la Europa continental durante el periodo de entreguerras $-{ }^{15}$ en buena parte de las ocasiones no ha parecido interpretar de una manera adecuada cuál es la verdadera función de la Constitución democrática, pretendiendo identificar en ella un problema necesitado de solución que, en realidad, no puede ser calificado como tal. ${ }^{16}$ En realidad, la citada teoría -que sólo ha parecido atenuarse en los estados actuales de manera reciente- ha pretendido ofrecer una solución que no ha hecho sino generar un verdadero problema democrático. ${ }^{17}$

\subsection{La defensa de la Constitución}

La supuesta paradoja de la democracia ha pretendido ser solucionada en la

\footnotetext{
${ }^{13}$ Sobre ello véase en la teoría material clásica C. Schmitt, Verfassungslehre, Ed. Duncker \& Humblot, Berlin, 1989, pp. 24-25. Por su parte, en la doctrina actual véase E. Denninger, "Verfassungstreue und Verfassungsschutz", Veröffentlichungen der Vereinigung der Deutschen Staatsrechtslehrer, No. 37, 1979, p. 15.

${ }^{14}$ Cfr. G. Röllecke, "Verfassungstreue und Schutz der Verfassung”, en Idem., Augeklärter Positivismus. Ausgewählten Schriften zu den Voraussetzungen des Verfassungsstaates, Ed. C. F. Müller, Heidelberg, 1995, pp. 165ss.

${ }^{15}$ Véase con carácter general L. Álvarez Álvarez, "La defensa de la Constitución durante el periodo de entreguerras”, Revista de Historia Constitucional, No. 7, 2006, pp. 229ss.

${ }^{16}$ Esta construcción ha pretendido presentarse en la doctrina como una reacción frente al modelo de democracia procedimental que, propugnada por el positivismo instaurado en Europa ya a finales del siglo XIX, había sido adoptada en la Constitución de Weimar de 1919. Pues bien, la comentada teoría de defensa de la democracia achacó a aquel modelo procedimental de democracia, haber sido el que legitimó la supresión de la Constitución de Weimar a través de los propios procedimientos democráticos, dándose cauce sucesivamente a la más elemental negación de la dignidad humana por parte del régimen nacionalsocialista.

${ }^{17}$ Sin embargo, ha sido verdaderamente curioso apreciar cómo con arreglo a los mismos presupuestos metodológicos adoptados por las teorias que han pretendido proceder a la solución del denominado dilema democrático escenificado en el contexto de la Constitución de Weimar de 1919, se ha llegado incluso a legitimar el propio advenimiento del régimen socialista. Cfr. C. Schmitt, "Der Führer Schutzt das Recht", en C. Schmitt, Positionen und Begriffe: im kampf mit Weimar-Genf-Versailles, 1923-1939, Ed. Duncker Ct Humblot, Berlin, 1988, p. 200; véase también al respecto "Die legale Weltrevolution. Politischer Mehrwert als Prämie auf juristiche legalität und Superlegalität”, Der Staat, No. 17, 1978, pp. 332ss.
} 
ciencia del derecho constitucional a través de la categoría de la defensa de la Constitución. Esta construcción parte de la distinción metodológica entre las normas jurídico-positivas y determinados fines, principios o valores que no resultan coincidentes en su naturaleza con aquéllas. ${ }^{18}$ De acuerdo con esta distinción metodológica, asociada a una concepción material de la Constitución, la defensa de ésta ha servido de base para declarar ilícitas las actividades que, aun respetando los procedimientos democráticos previstos en el texto constitucional positivo, pretendan suprimir el orden axiológico sobre el que descansa la Constitución democrática. Como se puede apreciar, el destinatario de la norma de defensa de la Constitución no es el que se denomina infractor -sólo definible a partir de las normas positivas- sino el enemigo de lo que se considera como la verdadera Constitución del Estado. ${ }^{19}$

De lo recientemente afirmado cabe apreciar cómo lo que pretende la categoría de la defensa de la Constitución es establecer un límite material a la función de la Constitución democrática consistente, tal y como se ha visto con anterioridad, en permitir la canalización de diferentes expectativas sociales en el seno del sistema jurídico. En efecto, la defensa de la Constitución pretende impedir la introducción en el ordenamiento jurídico de aquellas expectativas que persigan fines contrarios al sustrato axiológico sobre el que se edifica el texto constitucional democrático. Ésa es la función que se ha imputado, por ejemplo, al Art. 21.2 de la Ley Fundamental de Bonn, en la que se dispone que los partidos de cuyos "fines o de la actividad de sus miembros, se deduzca su pretensión de suprimir o menoscabar el orden democrático liberal [...] son inconstitucionales”. ${ }^{20} \mathrm{La}$ presente disposición se ha concebido como una norma positiva destinada a garantizar la eficacia del orden axiológico sobre el que descansa el texto constitucional alemán de 1949. ${ }^{21}$

\footnotetext{
${ }^{18}$ Cfr. C. Schmitt, Verfassungslehre, Op. cit., pp. 23-24.

${ }^{19}$ Véase originariamente C. Schmitt, Der Begriff des Politischen, Text von 1932 mit einem Vorwort und drei Corollarien, 3a edición, Ed. Duncker \&t Humblodt, Berlin, 1963, p. 29. También E. Denninger, "Verfassungstreue und Verfassungsschutz", Op. cit., p. 15, así como del mismo autor "Der Schutz der Verfassung", en E. Benda, W. Maihofer y H.-J. Vogel (Edits.), Handbuch des Verfassungsrechts, Ed. de Gruyter, Berlín, Nueva York, 1983, pp. 1293ss.

${ }^{20}$ K. Stern, Das Staatsrecht der Bundesrepublik Deutschland, Op. cit., pág. 183. Esta función es la que también se le ha atribuido al Art. 18 de la misma Constitución alemana en el que se afirma que el Art. 18 de la Constitución alemana, en el que se dispone que pierden los derechos fundamentales los que atenten contra el orden democrático liberal. Cfr. W. Schmitt-Glaeser, Mißbrauch und Verwirkung der Grundrechte im politischen Meinungskampf, Op. cit., p. 59ss.

${ }^{21}$ Véase al respecto C. Gusy, "Die 'freiheitliche Demokratische Grundordung' in der Rechtsprechung des Bundesverfassungsgerichts”, Archiv des Öffentichen Rechts, No. 105, 1980, pp. 289-290 y M. Kutscha,
} 
Sin embargo, la presente función -que también se recoge en otros documentos constitucionales europeos ${ }^{22}$ no siempre se ha articulado a partir de normas positivas que sirven a la eficacia de valores que se estiman ubicados por encima del texto constitucional. En realidad, incluso en las ocasiones en las que la defensa de la Constitución aparece expresamente prevista en el texto constitucional, la función de la defensa de la Constitución se ha hecho valer a través de una construcción exclusivamente dogmática, al margen por tanto de las normas positivas del texto constitucional. Éstas aparecen, pues, como la plasmación declarativa de la norma de defensa de la Constitución que trae su causa al margen de la normatividad jurídico-positiva. Eso es lo que ha sucedido precisamente en el contexto de la citada Ley Fundamental de Bonn cuyo Art. 21.2 se ha entendido, en un determinado ámbito temporal, como la materialización parcial de la norma metapositiva de la defensa de la Constitución. ${ }^{23} \mathrm{Y}$ es que, en realidad, la categoría de la defensa de la Constitución aparece en su origen en la ciencia del derecho constitucional como una exigencia teórica deducida de la necesidad de tutelar la eficacia de un orden material que se presume subyacente al texto constitucional positivo. En efecto, como se ha afirmado por parte de la teoría material clásica de la Constitución, las normas del texto constitucional positivo no pueden servir de base para suprimir las decisiones políticas fundamentales consensuadas por el pueblo y que sustentan el documento constitucional. ${ }^{24}$ Ha sido precisamente esta

Verfassung und Streitbare Demokratie, Ed. Pahl-Rugententein, Colonia, 1979, pp. 82ss.

${ }^{22}$ Así por ejemplo en el Art. 3 de la Verbotsgesetz austriaca - norma de rango constitucional-se dispone que quedan prohibidos los partidos políticos que adopten la ideología nacionalsocialista. Cfr. P. Pernthaler, Allgemeine Staatslehre und Verfassungslehre, Ed. Springer, Viena-Nueva-York, 1986, pp. 320ss y F. Ermacora, Grundriss der Menschenrechte in Österreich, Ed. Manz, Viena, 1988, p. 207. Por su parte, en la Constitución italiana, en la xil disposición transitoria y final, se afirma que está prohibida cualquier reorganización del disuelto partido fascista. Véase al respecto sobre ello A. Pizzorusso, "Disposizioni transitorie e finali xı”, en G. Branca (Edit.), Commentario della Costituzione, Ed. Zanichelli, Bolonia, 1975, p. 198. En la jurisprudencia constitucional, véanse las sentencias 645/1952, 74/1958, 15/1973. ${ }^{23}$ Véase sobre esta tesis, K. Stern, Das Staatsrecht der Bundesrepublik Deutschland, t. 1, Ed. C. H. Beck, München, 1977, p. 175; A. Sattler, Die rechtliche Bedeuntung die Entscheidung der Streitbare Demokratie, Ed. Nomos Verlagsgessellschaft, Baden-Baden, 1982, pp. 31ss y 62, y H. U. Klein, "Verfassungstreue und Schutz der Verfassung”, Veröffentlichungen der Vereinigung der Deutschen Staatsrechtslehrer, No. 37, 1978, pp. 63ss.

${ }^{24}$ Véase C. Schmitt, Verfassungslehre, Op. cit., pp. 24-25. Sobre la aplicación de la doctrina de la defensa de la Constitución al ámbito del principio federal -si bien de manera quizás equívoca no se la ha conceptualizado por la doctrina actual como defensa de la Constitución-, véase en particular, desde la teoría integracionista, a partir de su concepción material, R. Smend, "Ungeschriebenes Verfassungsrecht im Monarchischen Bundestaat”, Op. cit., pp. 56-57. También la defensa de la Constitución se halla en el trasfondo de la doctrina de la lealtad interorgánica, difundida en la ciencia del derecho constitucional desde los años 70 del siglo pasado. Véase al respecto W.-R. Schenke, Verfassungsorgantreue, Ed. Duncker \&t Humblot, Berlin, 1977, p. 26-27. 
construcción material clásica la que se ha utilizado en un principio para la construcción de la democracia militante, acuñada a mitad del siglo xx en la jurisprudencia del Tribunal Constitucional Federal alemán. ${ }^{25}$ Como se puede ver, la norma de defensa de la Constitución aparece como una exigencia dogmático-jurídica, de naturaleza metapositiva, derivada de la preexistencia de un sustrato político-social -al que se atribuye obviamente una naturaleza jurídica- destinada a garantizar la función de la Constitución democrática. No obstante, como se verá más adelante, esta construcción típicamente material ha ido perdiendo sus perfiles originarios, transitando hacia una formalización de la misma, deshaciéndose paulatinamente de sus presupuestos originariamente materiales. ${ }^{26}$ Ya se verá por qué.

Sin embargo, esta función de la defensa de la Constitución democrática consistente en declarar ilícitas las conductas de los enemigos del sustrato axiológico sobre el que descansa el documento constitucional democrático ${ }^{27}$ sólo resulta viable a partir lógicamente de la satisfacción de un concreto presupuesto. En efecto, el adecuado ejercicio de la función normativa de la defensa de la Constitución democrática sólo cobra sentido si, previamente, se parte del carácter intangible del su objeto..$^{28}$ En efecto, sólo si ciertas expectativas no son susceptibles de constitucionalización, pueden sustraerse las mismas al debate democrático. Dicho de otra manera, si las expectativas sociales no pueden conformar el contenido de la voluntad normativa del Estado -por así decir, el output del procedimiento democrático- cabe además prohibir que aquéllas se introduzcan en el procedimiento de la formación de la voluntad democrática -es decir, en el input del procedimiento democrático de toma de decisiones. ${ }^{29}$

\footnotetext{
${ }^{25}$ Como puso de manifiesto el citado Tribunal, del pluralismo de fines y valores resultan excluidos de la formación de la voluntad estatal determinados principios fundamentales que, aun cuando sean perseguidos mediante procedimientos democráticos, son reconocidos como valores absolutos y por ello deben ser defendidos decididamente frente a cualquier ataque. Cfr. BVerfGE., 5, 85 (139). Véanse también las BVerfGEE 13, 46 (50); BVerfGE 28, 36 (48); 30, 1 (20); 39, 334 (349).

${ }^{26}$ Ya desde la BVerfGE 10, 56 (81). Véase sobre la paulatina mutación del concepto de democracia militante en la doctrina E. Jesse, "Streitbare Demokratie in Vergangenheit, Gegenwart und Zukunft. Eine umstrittene Konzeption zwischen Kontinuität und Wandel”, en Konrad Löw (Edit.), Terror und Extremismus in Deutschland. Ursachen, Erscheinungsformen, Wege zur Überwindung, Ed. Duncker At Humblot, Berlin, 1994, pp. 11ss. También el reciente trabajo de J. Schaefer, Grundlegung einer ordoliberalen Verfassungstheorie, Ed. Duncker \&t Humblot, Berlin, 2007, pp. 23ss.

${ }_{27}$ Sobre las diferentes conceptualizaciones del enemigo de la Constitución, Cfr. W. Gansser, "Verfassungswidrig - verfassungsfeindlich - extremistish - Zur abgrenzung der Beggriffe", Bayerische Verwaltungsblätter, No. 18, 1980, pp. 545ss.

${ }^{28}$ Véase E. Bulla, "Die Lehre von der Streitbaren Demokratie. Versuch einer kritischen Analyse unter besonderer Berücksichtigung der Rechtsprechung der Bundesverfassungsgerichts", Archiv des Öffentlichen Rechts, No. 98, 1973, p. 356.

${ }^{29} \mathrm{Sin}$ embargo, ya en la construcción de este objeto metapositivo de la norma de defensa de la Consti-
} 
Por eso, la función de la norma defensa de la Constitución plasmada en el Art. 21.2 de la Ley Fundamental de Bonn encuentra su justificación dogmática en el Art. 79.3, ${ }^{30}$ en aquellos casos en los que la argumentación sobre la defensa de la Constitución ha girado en torno a las disposiciones positivas del texto constitucional, ya adopten una función constitutiva de la tutela de la Constitución democrática o, lo que ha sido más frecuente, asuman una función declarativa de una norma metapositiva preexistente. Por el contrario, en las ocasiones en las que la defensa de la Constitución ha sido objeto de una construcción exclusivamente dogmática -lo que ha sucedido principalmente en los primeros momentos de aprobación de la Ley Fundamental de Bonn - la naturaleza metapositiva del orden axiológico subyacente al texto constitucional democrático, y su consiguiente inmutabilidad por los procedimientos jurídico-positivos dispuestos en el mismo, aparece como el presupuesto teórico para el adecuado ejercicio de la norma de defensa de la Constitución. ${ }^{31}$

\subsection{La defensa del Estado}

En realidad, la doctrina de la defensa de la función de la Constitución democrática que se acaba de exponer y que ha sido desarrollada principalmente por la doctrina constitucional del periodo de entreguerras pretende reaccionar, como ha quedado dicho, frente al modelo de democracia y de

tución, esta doctrina incurre en una quiebra con el propio principio democrático, cuya función pretende ser garantizada de manera paradójica por la presente doctrina. En efecto, el primer problema se deriva de la definición del titular de la facultad jurídica para identificar su contenido. En realidad, tal facultad no se atribuye a los sometidos al ordenamiento jurídico -a los que de acuerdo con el principio democrático tendría que corresponderles tal tarea $(\mathrm{H}$. Kelsen, Wesen und Wert der Demokratie, Op. cit., $\mathrm{p}$. 20) - sino a un órgano a quien se le capacita para concretar cuáles son las materias consensuadas por el pueblo. Véase C. Schmitt, Verfassungslehre, Op. cit., p. 83 y R. Smend, "Verfassung und Verfassungsrecht”, en Idem., Staatsrechtlichen Abhandlungen, Ed. Duncker \& Humblot, Berlin, 1968, p. 136ss.

${ }^{30}$ Véase al respecto P. Häberle, "Die Menschenwürde als Grundlage der staatlichen Gemeinschaft", en J. lsensee y P. Kirchhof (Edits), Handbuch des Staatsrecht, t. I -Grundlagen von Staat und Verfassung, Ed. C. F. Müller, Heidelberg, 1987 pp. 346ss y T. Maunz, “Artikel 79, ı”, en T. Maunz y G. Dürig (Edits.), Grundgesetzkommentar, t. 11, Ed. C. F. Müller, Heidelberg, 1993, p. 16.

${ }^{31}$ Véase esta consecuencia de las dogmáticas materiales clásicas en C. Schmitt, Verfassungslehre, $0 p$. cit., pp. 24-25. Cfr. B.-0. Bryde, “Artikel 79. ı”, en 1. von Münch, Grundgesetzkommentar, Op. cit., p. 243. Para el citado autor, el Art. 79.3 de la Ley Fundamental no tendría sino un valor meramente declarativo de una inmutabilidad consustancial a la materialización del concepto de Constitución. Un trabajo actual que intenta poner de manifiesto los modos de argumentación material y el posterior tránsito hacia una formalización de la función de la democracia militante puede verse en H.-E. Dieckmann, Überpositives Recht Als Prufungsmassstab Im Geltungsbereich Des Grundgesetzes Eine Kritische Wurdigung Der Rezeption Der Radbruchschen Formel und Des Naturrechtsgedankens in Der Rechtsprechung, Ed. Duncker \& Humblot, Berlin, 2006, pp. 35ss. 
su defensa planteada por el positivismo, difundido en Europa durante el último tercio del siglo xix. Este modelo de democracia, plasmado en la Constitución de Weimar de $1919,{ }^{32}$ fue hecho responsable de legalizar la supresión de la democracia por medio de los mismos procedimientos democráticos. Este concreto modelo ha sido calificado por la doctrina actual como de defensa del Estado, con el que se pretende hacer referencia a un conjunto de normas de naturaleza jurídico-positiva que tienen como función proteger a aquéllas frente a su posible infracción..$^{33}$ En consecuencia, la diferencia entre defensa de la Constitución y defensa del Estado se ubica, ante todo, en el objeto de protección: fines metapositivos-normas jurídicopositivas. En ese sentido, en el seno de la defensa del Estado únicamente cabe hablar coherentemente de infractores, no de enemigos, si con esta categoría se pretende aludir -como realizan las teorías anteriormente expuestas- a una contrariedad con un orden valorativo metapositivo que, de acuerdo con los presupuestos plenamente positivos que subyacen a la categoría de la defensa del Estado, no pueden existir.

Sin perjuicio de que esto sea así efectivamente, uno de los equívocos en los que ha incurrido la teoría clásica de la defensa de la Constitución es que ha identificado equívocamente la negación de la existencia de enemigos por parte de la concepción positivista de la democracia con su indiferencia respecto de las expectativas o de los fines políticos eventualmente constitucionalizables. Ésta es la premisa que sostiene la denominada paradoja de la democracia y sobre la que se edifica toda la teoría de la defensa de la Constitución. Sin embargo, hay buenos motivos para pensar que dicha premisa ha de ser considerada, en realidad, como falsa. En efecto, también desde presupuestos plenamente positivos es posible afırmar que la propia Constitución democrática, en uso de su soberanía, puede haber optado por sustraer al cambio determinadas normas constitucionales y, además, prohibir a los sujetos a ellas la persecución de las mismas. También desde un punto de vista positivo la defensa del Estado puede llegar a interpretar coherentemente los mecanismos dispuestos en ciertas constituciones actuales, como por ejemplo, el Art. 21.2 vinculado al Art. 79.3, ${ }^{34}$ de la Ley Fundamental de

\footnotetext{
${ }^{32}$ Cfr. R. Thoma, “Grundbegriffe und Grundsätze”, en H. C. Nipperdey (Edit.), Die Grundrechte und Grundpflichten der Reichverfassung, Ed. Keip, Francfort, 1975, p. 144.

${ }^{33}$ Véase D. Rauschning, Die Sicherung der Beachtung der Verfassungsrecht, Ed. Gehlen, Berlin, 1969, p. 14. En concreto, la contraposición de esta categoría de la defensa del Estado con la defensa de la Constitución puede verse en K. Stern, Das Staatsrecht der Bundesrepublik Deutschland, Op. cit., p. 151ss.

${ }^{34}$ Véase sobre esta interpretación plenamente positiva del Art. 79.3 de la Constitución alemana E.

Wegge, Zur normative Bedeutung des Demokratieprinzips nach art. 79. 3 Abs. 3 GG, Ed. Nomos
} 
Bonn, sin más diferencia que no definir a sus destinatarios como enemigos distintos a los infractores..$^{35}$ El enemigo de la Constitución, con arreglo a parámetros exclusivamente positivos, sólo puede ser caracterizado como un infractor cualificado por la naturaleza intangible de su objeto. ${ }^{36}$ Eso es lo que permite explicar que en la actualidad, teniendo en cuenta la más actual jurisprudencia del Tribunal Constitucional Federal alemán, pueda ser viable hablar de una democracia militante formalizada más compatible con las exigencias de la defensa del Estado que con las originariamente asumidas de la defensa de la Constitución. En efecto, si bien en el caso de la ilegali-

Verlagsgesellschaft, Baden-Baden, 1996, pp. 28ss. La imposibilidad de reforma de ciertas materias ha sido usualmente asociada a que las mismas asumen una naturaleza metapositiva, en la medida en que no se encuentran sometidas a un acto de voluntad jurídico-positivo del poder constituyente constituido. Sin embargo, este resultado no tiene por qué significar desposeer a tales materias de una naturaleza plenamente positiva, ya que, en realidad, tales materias pueden en ser sí mismas la expresión de un acto de voluntad por parte del sujeto habilitado para ello: el poder constituyente.

${ }^{35}$ Pero es que, además, es precisamente de esta manera cuando es posible soslayar los problemas en los que incurre la teoría de la defensa de la Constitución. Por un lado, la construcción positiva del objeto de defensa del Estado permite soslayar los problemas de inseguridad jurídica que aquejan a la construcción de la defensa de la Constitución al identificar su objeto de tutela a partir de la vigencia social de determinadas materias, esto es, desde el ser y no desde el deber ser. Véase C. Schmitt, Verfassungslehre, $\mathrm{Op}$. cit., p. 83. Por otro lado, el objeto de una norma de lealtad como defensa del Estado - contrariamente a lo que sucede cuando ésta se concibe como defensa de la Constitución-se condiciona verdadera y exclusivamente a la voluntad de los sometidos al ordenamiento jurídico, deducida de los procedimientos jurídico-positivos de reforma constitucional, satisfaciéndose una de las exigencias del principio democrático. De esta manera ningún órgano aparece apoderado para deducir el contenido de la voluntad popular, imputándolo a ésta, sino que resulta determinado por aquel órgano que más fiel y directamente puede expresarla: el cuerpo electoral. Cfr. H. Kelsen, Vom Wesen und Wert der Demokratie, Op. cit., p. 16-17 y 20.

${ }^{36}$ Pero es que, además, cuando la defensa de la Constitución democrática se plantea en términos de derecho positivo es posible acomodar su tutela a las exigencias dogmáticas del principio democrático. En efecto, como se ha puesto de manifiesto con anterioridad, la función del principio democrático consiste en permitir que las diferentes expectativas - de carácter político, religioso, moral- puedan canalizarse procedimentalmente en el seno del ordenamiento jurídico, pudiendo llegar a conformar el contenido de la voluntad del Estado. Siendo esto así, parece tener que deducirse que la pretensión de un Estado democrático es diferenciar al ordenamiento jurídico de los demás órdenes sociales que también regulan la conducta humana En ese sentido, puede afirmarse que la diferenciación del ordenamiento jurídico se presenta como una exigencia dogmática ineludible del principio democrático. Sobre esta relación entre el principio democrático y diferenciación del ordenamiento. Cfr. B. Aláez Corral, Los límites materiales a la reforma de la Constitución de 1978, Ed. Centro de Estudios Políticos y Constitucionales, Madrid, 2000, pp. 115ss. Esta exigencia aparece verdaderamente posible cuando el derecho se define en términos estrictamente positivos, concibiéndose como un conjunto de normas que expresan el sentido objetivo de actos de voluntad humana. Véase J. Austin, The province of jurisprudente determined, (reimpresión de

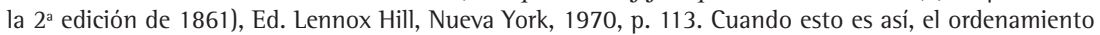
jurídico puede diferenciarse, en primer lugar, de otros órdenes sociales cuyas normas proceden de voluntades divinas o racionales, y no propiamente humanas. Pero es que, además, por otro lado, cuando el ordenamiento jurídico se concibe con arreglo a parámetros positivos, sus normas se presentan como la objetivación de actos de voluntad humana, distinguiéndose así la realidad de la norma, el ser y del deber ser, que confunde la teoria de la defensa de la Constitución democrática. Cfr. H. Kelsen, Allgemeine Staatslehre, Unveränderter fotomechanischer Nachdruck der Ersten Auflage von 1925, Ed. Max Gehlen, Berlin, 1966, pp. 8-9, 18-19; H. Kelsen, Reine Rechtslehre, Ed. Franz Deuticke, Viena, 1976, p. 219. 
zación de los partidos SRP y KPD, en los años 1952 y 1956 respectivamente, se ha optado por un modelo de defensa de la democracia compatible con las exigencias de la defensa de la Constitución, en la sentencia pronunciada en 2003 en el contexto de la demanda de ilegalización presentada contra el NPD se sientan las bases para una formalización o, si se quiere, de una procedimentalización de los mecanismos de defensa de la Constitución democrática.$^{37}$ Como se puede apreciar, la ilegalización de los enemigos puede tener sentido plenamente en el seno de los presupuestos de la defensa del Estado. En realidad, la teoría de la defensa de la Constitución democrática se aferra equívocamente a la imposibilidad de hablar de enemigos distintos a los infractores en el seno de una concepción positivista de la democracia para achacarle de manera falsa su carácter axiológicamente neutral.

Sin embargo, lo que sí es cierto es que cuando la defensa de la Constitución democrática se plantea en términos de defensa del Estado, esto es, desde planteamientos exclusivamente positivos, sí cabe que toda la Constitución pueda ser objeto de reforma constitucional, si es que la soberana voluntad constitucional ha tenido a bien reconocerlo. Por ello, la defensa del Estado, si bien puede efectivamente tener por objeto la protección de normas constitucionales inmodificables, como sucede en las Constituciones alemana o italiana, legitimándose así, además, la posibilidad de identificar a sus enemigos e ilegalizarlos, puede identificar su objeto en normas susceptibles de cambio, ${ }^{38}$ según sucede en el caso de la Constitución española de $1978 .{ }^{39}$ En estos términos, no se respondería frente a los fines antidemocráticos sino tan sólo respecto de los medios utilizados para su consecución. ${ }^{40}$ Es más, esta consecuencia, en el seno de la doctrina de la defensa del Estado ni siquiera tendría que asociarse necesariamente a la posibilidad total de reforma de la Constitución. Con arreglo a parámetros

\footnotetext{
37 Véase BVerfGE $107,339$.

${ }^{38}$ La posibilidad de reforma total de la Constitución se ha presentado como la expresión del principio de neutralidad del Estado, que conduce a la imposibilidad de exigir una identificación ideológica con determinadas materias recogidas en la Constitución (principio de no identificación). Véase respectivamente, en lo que se refiere a los aludidos principios, H. Krüger, Allgemeine Staatslehre, Ed. Kohlhammer, Stuttgart y otros, 1966, pp. 178ss y E.-W. Böckenförde, "Das Recht der Gewissenfreiheit", en Idem., Staat, Verfassung, Demokratie, Ed. Suhkamp, Francfort, 1991, p. 226.

${ }^{39}$ Sobre la posibilidad de reforma total de la Constitución española, véase 1. de Otto y Pardo, Derecho constitucional. Sistema de fuentes, Ed. Ariel, Barcelona, 1987, pp. 63ss, J. Pérez Royo, La reforma de la Constitución, Ed. Congreso de los Diputados, Madrid, 1987, pp. 207-208 y B. Aláez Corral, Los límites materiales a la reforma de la Constitución, Op. cit., pp. $290 \mathrm{ss}$.

${ }^{40}$ Véase particularmente esta consecuencia para el caso español que, como se ha visto, permite la reforma total de sus normas constitucionales, 1. de Otto y Pardo, Defensa de la Constitución y partidos politicos, Ed. Centro de Estudios Constitucionales, Madrid, 1985, p. 27.
} 
exclusivamente positivos, podría llegar a aceptarse que una Constitución declare intangibles ciertas materias y, por el contrario, renuncie a declarar ilícitos los fines políticos, sino simplemente acciones contrarias a su objeto, tal y como sucede, por ejemplo, en la Constitución francesa. ${ }^{41}$ Eso es lo que permite la positividad, la configuración soberana del modelo de defensa de la Constitución democrática, ya sea en los mismos términos que los propuestos por la doctrina clásica de la defensa de la Constitución, o con arreglo a premisas bien distintas. Pues bien, como se verá seguidamente, esta libertad que reconoce la positividad y, en definitiva, la soberanía del ordenamiento, a la configuración del instrumentario jurídico-normativo destinado a la protección de la Constitución democrática permitirá que dicha tutela sea capaz de adecuarse de una mejor manera a las exigencias dogmáticas del principio democrático.

\section{La función normativa de la Constitución democrática al servicio de la eficacia DEL ORDENAMIENTO}

\subsection{La función de la Constitución democrática y la eficaCia del ORdenamiento JURÍDICO}

La eficacia generalizada del ordenamiento jurídico se presenta como una condición dogmática indispensable para que el derecho pueda ejercer válidamente su función consistente en regular las condiciones del ejercicio de la fuerza. ${ }^{42}$ El derecho, si no pretende quedar relegado a una mera

\footnotetext{
${ }^{41}$ En efecto, si bien la Constitución francesa de 1956 ha declarado irreformable el carácter republicano del Estado (Art. 89.5), ha renunciado, como ha entendido mayoritariamente la doctrina, a declarar ilícitos aquellos comportamientos que persigan fines contrarios a la República, sobre el contenido de la norma de lealtad dirigida a los partidos políticos del Art. 4 del texto constitucional. Véase 1. Canu, Der Schutz der Demokratie in Deutschland und Frankreich, Ed. Leske + Budrich, Opladen, 1997, pp. 98 y 188. ${ }^{42}$ Acerca de esta concepción de la eficacia generalizada del ordenamiento jurídico como una condición fáctica para la presuposición de su validez, véase H. Kelsen, Reine Rechtslehre, Op. cit., p. 219 y Allgemeine Staatslehre, $O p$. cit., pp. 18-19. La vinculación entre validez y eficacia representa una constante en las diferentes concepciones del ordenamiento y de la Constitución. Véase particularmente, en lo que se refiere a las dogmáticas materiales de Constitución, C. Schmitt, Verfassungslehre, Op. cit., pp. 23-24, R. Smend, "Verfassung und Verfassungsrecht", Op. cit., p. 127, M. Hauriou, Prècis de Droit Costitutionnel, Ed, Sirey, Paris, 1923, p. 76 y C. Mortati, La Costituzione in senso materiale, Ed. Giuffrè, Milan, 1940, p. 133. Sin embargo, en estas teorías materiales se identifican validez y eficacia, ser y deber ser, esto es, la validez del ordenamiento jurídico tiene lugar cuando éste es eficaz. De tal manera, la eficacia no se presenta en la doctrina material como una condición de validez del ordenamiento jurídico, sino como fundamento mismo de ella. El problema al que conduce esta fusión entre validez y eficacia es, sin embargo, su incapacidad para distinguir norma y realidad, algo imprescindible si el derecho se concibe como un orden prescriptivo (deber ser) que tiene por objeto regular la conducta humana (ser). Véase al respecto un análisis crítico en H. Kelsen, "Der Staat als Integration", en Idem., Drei Kleine Schriften,
} 
construcción ideal carente de toda entidad práctica, sólo puede considerarse válido si es susceptible de provocar a grandes rasgos una ordenación real de la conducta humana. ${ }^{43}$ Cuando esto sucede, el derecho puede diferenciarse adecuadamente de otros órdenes sociales, como la política, la moral o la religión, que también desempeñan la función de regular la conducta humana, aunque mediante normas que predeterminan otra clase de sanciones (políticas, morales o divinas). En ese sentido, cabe afırmar que la eficacia generalizada del ordenamiento jurídico se presenta como una condición funcional indispensable de la diferenciación del derecho como sistema social. ${ }^{44}$ Pues bien, como se verá seguidamente, esta condición funcional del ordenamiento jurídico queda garantizada en buena medida cuando aquél satisface dos elementos estructurales: la supremacía constitucional y el principio democrático. Lo que se pretende demostrar es cómo la función normativa de una Constitución democrática que se conciba como norma suprema es precisamente garantizar aquella condición dogmático-funcional del ordenamiento jurídico.

\footnotetext{
Ed. Scientia, Aalen, 1994, pp. 12ss.

${ }^{43}$ Si se tiene en cuenta, como se ha visto, que la función del ordenamiento jurídico es regular las condiciones de ejercicio de la fuerza, su eficacia generalizada debe de medirse precisamente a partir del grado de eficacia en el ejercicio de dicha función, es decir, de la imposición por la fuerza del cumplimiento de sus normas. Por ello, un ordenamiento en el que todas sus normas se cumpliesen voluntariamente y, por tanto, no se desempeñara nunca su función, no podría considerarse eficaz y, por tanto, válido. Por tanto, para que un ordenamiento sea generalmente eficaz tiene que darse un cierto grado de incumplimiento de sus normas que habilite el ejercicio de su función. Sin embargo, este grado de incumplimiento no podria llegar a presentar una entidad tan elevada que el Estado no pudiera llegar a imponer coactivamente el cumplimiento de sus normas. Cfr. H. Kelsen, Reine Rechtslehre, Op. cit., pp. 220-221.

${ }^{44}$ La concreción del necesario grado de eficacia generalizada que ha de tener un ordenamiento jurídico para que pueda considerarse válido resulta, en realidad, difícilmente cuantificable, y al realizarse en el ámbito del ser, corresponde a ciencias afines a las jurídicas. A pesar de ello, parece claro que, en términos normativos, la eficacia generalizada del ordenamiento no puede encontrarse amenazada de igual manera por la ineficacia de las normas jurídicas que ocupan un rango inferior en el ordenamiento jurídico que por aquélla que afecte a la norma fundamentadora de la validez de sus normas: la Constitución. Un ordenamiento jurídico difícilmente puede ser eficaz en su conjunto si su fundamento de validez no resulta también eficaz. Cfr. H. Kelsen, "Vom Geltungsgrund des Rechts", en H. Klekatsky, R. Marcic y H. Schambeck (Edits.), Die Wiener Rechtstheoretische Schule, t. 11, Ed. Europa, Viena, Francfort, Zurich, 1968, p. 1422. Por ello, en la precisión de la eficacia generalizada del ordenamiento, la eficacia de la Constitución presenta un papel nuclear. Eso es lo que explica que las normas que pretenden garantizar la eficacia, muy particularmente, de las normas constitucionales, desempeñen de manera más intensa la función tutelar de la eficacia generalizada del ordenamiento jurídico y su diferenciación del resto de órdenes normativos sociales que el resto de las normas jurídicas que pretenden garantizar la eficacia de las demás normas del ordenamiento. $Y$ así, no tienen igual incidencia sobre la eficacia generalizada del ordenamiento jurídico las normas que responden frente a las infracciones de la Constitución -ya sea tutelando la eficacia puntualmente de los principios estructurales (lealtad constitucional) o genéricamente la de la totalidad de sus normas- que, por el contrario, las que tratan de garantizar la eficacia de normas infraconstitucionales, como por ejemplo, las que tratan de asegurar la eficacia normativa en el ámbito civil, penal o laboral; si bien en muchos casos -en la medida en que desarrollan o concretan normas constitucionales- acaban también garantizando en último extremo la eficacia de la Constitución.
} 
Esta pretensión de que el ordenamiento jurídico sea eficaz se pone de relieve, en primer lugar, con el elemento de la supremacía constitucional. Esta supremacía, que se manifiesta en la indisponibilidad de sus normas frente a cualquier potestad de normación reconocida en el seno del ordenamiento, no despliega exclusivamente sus efectos en el plano de la validez -declarando derogadas cualesquiera normas que contravengan lo dispuesto en la norma constitucional-, sino también en el de la eficacia. La voluntad de la Constitución de hacer indisponibles sus normas manifiesta, en realidad, su pretensión de que sean eficaces, esto es, de que se comprendan como una regulación estable del comportamiento humano, no sometida a la voluntad del legislador. ${ }^{45}$ Esta pretensión teórica no surge cuando la Constitución se concibe como una ley reforzada, no jerárquicamente superior a ella. ${ }^{46}$

Pero, aunque es cierto, efectivamente, que una Constitución que se conciba como una norma suprema expresa su intención de que tanto ella misma, como el resto de las normas jurídicas fundamentadas en su validez en ella sean eficaces, su pretensión de eficacia resulta ratificada cuando la Constitución, como norma suprema, institucionalice su propio cambio mediante procedimientos democráticos. En realidad, la posibilidad de cambio democrático sienta las bases para que la Constitución como norma suprema pueda ser verdaderamente eficaz. En efecto, la eficacia de una Constitución se garantiza de una mejor manera cuando se permite que las diferentes expectativas (políticas, morales, religiosas...) puedan canalizarse lícitamente a través de los procesos democráticos reconocidos en ella, evitándose que tengan que ser perseguidas mediante cauces contrarios al ordenamiento, con el consiguiente peligro que ello puede entrañar para su propia eficacia ${ }^{47}$ Esa función es la que, como se ha visto con anterioridad, pretende desempeñar la Constitución democrática.

${ }^{45}$ Cfr. R. Thoma, "Allgemeine Bedetung der Grundrechte", en H.-C. Nipperdey (Edit.), Die Grundrechte und Grundpflichten der Reichsverfassung, Kommentar zum zweiten Teil der Reichsverfassung, t. 1, Ed. Ferdinand Keip, Francfort, 1975, pp. 8-9. Sobre ello, en la historia constitucional europea véase R. Wahl, "Der Vorrang der Verfassung", Op. cit., p. 498.

${ }^{46}$ Cfr. J. Jellinek, Allgemeine Staatslehre, Ed. Julius Springer, Berlin, 1929, p. 531-532.

${ }^{47}$ Por ello el principio democrático, en la medida en que contribuye a la eficacia de la Constitución, aparece como una norma destinada a garantizar también su supremacía. Acerca de esta relación entre la posibilidad del cambio de las normas constitucionales y la eficacia de la Constitución, véase B. Aláez Corral, Los límites materiales a la reforma de la Constitución de 1978, Op. cit., pp. 115ss. Sin embargo, más adelante se tendrá la oportunidad de poner de manifiesto cómo el principio democrático se presenta también como una norma al servicio de la positividad del ordenamiento. 


\subsection{LA INTANGIBILIDAD DEL PRINCIPIO DEMOCRÁTICO Y LA FUNCIÓN NORMATIVA} de la Constitución democrática

Los dos modelos de defensa de la Constitución democrática anteriormente expuestos: la defensa de la Constitución y la defensa del Estado sirven, en realidad, de una manera distinta a la tutela de la función de la Constitución democrática, al servicio de la eficacia generalizada del ordenamiento jurídico. Teóricamente la categoría de la defensa de la Constitución, a través de una supuesta solución del dilema democrático, pretende presentarse como un instituto que sirve de mejor manera a la eficacia del ordenamiento al excluir del proceso de conformación de la voluntad democrática a sus enemigos, es decir, a quienes pretenden acabar con la democracia misma. Sin embargo, esta consecuencia, a la que se puede llegar, como se ha puesto de manifiesto, desde los presupuestos mismos de la defensa del Estado, presenta, con todo, algún problema con el ejercicio de la función de la Constitución democrática. En efecto, la exclusión de los enemigos de la democracia, trae como resultado que ciertas conductas queden automáticamente excluidas del sistema jurídico aun cuando sean perseguidas a través de los procedimientos democráticos. ${ }^{48}$ Pero, en realidad no sólo ciertas conductas, sino todas las que sean expresivas de opciones incompatibles con el orden axiológico subyacente al texto constitucional positivo. ${ }^{49}$

De esta manera, aquellas expectativas automáticamente excluidas del ordenamiento sólo pueden llegar a juridificarse cuando se instauran eficazmente como normas reguladoras del uso de la fuerza, negando eficacia a las actualmente válidas plasmadas en la Constitución democrática. Por ello, tal mecanismo de tutela de la democracia invoca a sus enemigos a infringir las normas de la Constitución, con el consiguiente riesgo para su

\footnotetext{
${ }^{48}$ En esa situación, recuérdese, quedaban algunas ideologías en el seno del Estado liberal no democrático del siglo XIX. Véase nuevamente E. Kaufmann, "Die Grenzen des Verfassungsmäßigen Verhantens nach den Bonner Grundgesetz, insbesondere: was ist unter einer freiheitlichen demmokratischen Grundordnung zu verstehen? Festvortrag aus dem 39. deutschen Juristentag 1951”, Op. cit., p. 97-98.

${ }^{49}$ En efecto, uno de los elementos definitorios de la categoría de la defensa de la Constitución es su contenido universal, al proyectar su pretensión de eficacia a todos los destinatarios de las materias que forman parte de ella y, además, lo que resulta extraordinariamente relevante, frente a todas las conductas procedentes de aquéllos. Sobre la caracterización de la defensa de la Constitución como una norma de contenido universal, véase E. Denninger, "Verfassungstreue und Schutz der Verfassung", $O p$. cit., p. 17. Como se puede apreciar, la universalidad de la defensa de la Constitución se extiende a su objeto (toda la Constitución metapositiva), a sus destinatarios (los sujetos cuya conducta es regulada por aquélla) y a sus conductas. Eso es lo que define precisamente al instituto de la defensa de la Constitución: la posibilidad de declarar ilícita cualquier conducta que, aun en cumplimiento de las normas positivas, lesione la eficacia del orden material subyacente a aquéllas.
} 
propia eficacia ${ }^{50} 0$, como se ha afirmado en la ciencia del derecho constitucional: a la revolución..$^{51}$ Pero por otra parte, cuando la Constitución democrática renuncia a la identificación de sus enemigos, lo que sólo puede suceder en el plano de la defensa del Estado, esto es, cuando el derecho se comprenda en términos exclusivamente positivos, se sientan las bases para la supresión de la democracia por medio de los procedimientos democráticos, presentando así igualmente riesgos para la propia Constitución democrática. Como se puede ver, ambos institutos: defensa de la Constitución y defensa del Estado presentan, apriorísticamente, problemas para la eficacia de la Constitución democrática.

En realidad, la eficacia de una Constitución constituye siempre una cuestión de grado. El problema reside en determinar de qué manera se protege mejor a la función normativa de una Constitución democrática. Posiblemente la mejor forma de tutelar la democracia sea una solución intermedia, una solución que no permitirá ofrecer la defensa de la Constitución, sino únicamente la defensa del Estado y los presupuestos jurídicopositivos sobre los que la misma se sustenta. Seguramente la mejor tutela de la eficacia del ordenamiento y la función democrática se produzca en aquella Constitución que permita su cambio, pero sustraiga a éste precisamente que quede abierta la posibilidad de cambio de sus normas, es decir, el principio democrático, tal y como sucede en las constituciones alemana e italiana. ${ }^{52}$ De esta manera, lo que se declara intangible es la propia función de la Constitución democrática, esto es, la apertura de las expectativas.

Esta inmutabilidad del propio principio democrático no queda adecuadamente asegurada en el ámbito de la defensa de la Constitución, ya que ésta acaba postulando la intangibilidad de toda materia que llegue a integrar el orden axiológico subyacente al texto constitucional positivo, que resulta determinado a partir de la vigencia social de determinadas materias. De esta manera, se acaba atribuyendo la intangibilidad a cualquiera de las que conformen su contenido, no necesariamente coincidente

${ }^{50}$ Véase E. Denninger, "Verfassungstreue und Schutz der Verfassung”, Op. cit., pp. 24; E.-W. Böckenförde, "Verhältensgewähr und Gessinungstreue? Sicherung der freiheitliche Demokratische in der Formen des Rechtsstaats", en Idem., Staat, Verfassung, Demokratie, Ed. Suhrkamp, Francfort, 1991, pp. 84ss y H. Goerlich, "Gedankenfreiheit und Treuepficht”, Zeitschrift für Beamten Rechts, No. 4, 1975, pp. 104 ss.

${ }^{51}$ Véase G. Röllecke, "Verfassungstreue und Schutz der Verfassung”, Op. cit., p. 169.

${ }^{52}$ Véase respectivamente K. Stern, "Die Bedeutung der Unantastbakeitsgarantie des Art. 79. 11 für die Grundrechte”, Juristiche Schulung, No. 5, 1985, p. 330 y L. Ventura, “Articolo 54”, en G. Branca (Edit.), Comentario della Costituzione. Rapporti politici, Op. cit., p. 56. 
con el principio democrático..$^{53}$ Por ello, la defensa de la Constitución no es del todo adecuada para tutelar la función normativa de la Constitución democrática. Sí puede serlo si la protección de su función se plantea en los términos de la defensa del Estado, correspondiendo a la voluntad soberana del texto constitucional positivo seleccionar y construir el objeto de su intangibilidad, pudiendo así identificarlo en el propio principio democrático como proceso de toma de decisiones. ${ }^{54}$

Sin embargo, es cierto que la voluntad soberana de la Constitución como norma de derecho positivo puede llegar a ser compatible con la posibilidad total de cambio de la Constitución. Es precisamente ante esta posibilidad frente a la que se ha construido, como se ha visto, la categoría de la defensa de la Constitución. Sin perjuicio de que la maximización de la función normativa de la Constitución democrática se optimiza, tal y como ha quedado dicho, cuando lo que se sustrae al cambio es la propia apertura constitucional, en sí mismo la posibilidad de reforma total de sus normas -como materialización de lo que se ha denominado principio de neutralidad del Estado, expresando la indiferencia constitucional respecto de las materias potencialmente constitucionalizables $-{ }^{55}$ no tiene que ser necesariamente criticable. ${ }^{56}$ Dicho de otra manera, una Constitución de-

\footnotetext{
${ }^{53}$ Y así, por ejemplo, la teoría material de la integración ha entendido que el Art. 3 de la Constitución de Weimar de 1919, relativo a los colores de la bandera forma parte de la unidad de sentido, es decir, de la verdadera Constitución del Estado. Cfr. R. Smend, "Verfassung und Verfassungsrecht", Op. cit., p. 217. Desde esta misma concepción material, en el contexto de la actual Ley Fundamental de Bonn, se aprecia también esta consecuencia, al haberse llegado a afirmar que la capitalidad del Estado alemán en Berlín ha constituido una decisión que pertenece al pueblo y que se ha conservado frente a la división histórica de las dos Alemanias. Cfr. R. Scholz, "Der Status Berlins”, en J. Isensee y P. Kirchhof (Edits.), Handbuch des Staatsrechts, tomo 1 - Grundlagen von Staat und Verfassung, Ed. C. F. Müller, Heidelberg, 1987, pp. 356ss. También sobre la base de una idéntica concepción material de la Constitución se ha llegado a afirmar igualmente en el seno de la Ley Fundamental de Bonn que el idioma alemán es una de las señas de identidad del ordenamiento alemán. Véase P. Kirchhof, "Die ldentität der Verfassung in ihren unabanderlichen Inhalten”, en J. Isensee y P. Kirchhof (Edits.), Handbuch des Staatsrecht der Bundesrepublik Deutschland, t. I - Grundlagen von Staat und Verfassung, Ed. C. F. Müller, Heidelberg, 1987, p. 800.

${ }^{54}$ Ello, por supuesto, no significa negar la total idoneidad de la defensa de la Constitución para la tutela de la función normativa de la Constitución democrática. Es cierto que en las teorías materiales clásicas, el contenido del sustrato axiológico sobre el que descansa el texto constitucional positivo se identificó principalmente en el principio democrático. Pero no es menos cierto que, sobre la base de las premisas metodológicas del razonamiento material, es posible que lleguen a sustraerse al cambio constitucional todas las materias que puedan conformar el orden axiológico subyacente al texto constitucional, lo que puede acabar en la intangibilidad de cualquier materia a aquel orden imputada; un aspecto que podría llegar a implicar una total supresión de la función de la Constitución democrática.

${ }^{55}$ Cfr. H. Krüger, Allgemeine Staatslehre, Op. cit., pp. 178ss y E.-W. Böckenförde, "Das Recht der Gewissensfreiheit”, Op. cit., p. 226.

${ }^{56}$ Este principio de neutralidad se contiene, por ejemplo, en el Art. 168 de la Constitución española,

al permitir a través de su reforma total que cualquier expectativa pueda llegar a integrar el contenido
} 
mocrática tal no supone la habilitación normativa de lo que se ha llamado la paradoja de la democracia, necesitada de una corrección. En efecto, en lo que positivo tiene, la posibilidad total de reforma de la Constitución permitiría que cualquier expectativa fuera objeto de positivación, incluso aquellas que pretendiesen acabar con la propia Constitución democrática. Sin embargo, habría que preguntarse si eso no sería más que un problema para su propia eficacia, una manifestación también de la pretensión de una Constitución suprema y democrática de ser eficaz. ¿0 ella no refuerza también su eficacia, su estabilidad y diferenciación como norma jurídicopositiva frente al resto de sistemas sociales -aunque acabe legitimando el cambio democrático - al abrirse a la positivación de cualquier expectativa? Con todo, ello no es óbice, como se ha puesto de manifiesto con anterioridad, para que la Constitución democrática garantice mejor su eficacia cuando declara intangible el propio principio democrático. ${ }^{57}$

\subsection{EL PRINCIPIO de NO IDENTIFICACIÓN DEL ESTAdO Y SU FUnCIÓN NORMATIVA de LA Constitución democrática}

Seguramente en la respuesta frente a la infracción de aquellas normas que sustraen al cambio el propio principio democrático, esto es, la propia posibilidad de cambio democrático deba de finalizar la tutela de la función normativa de la Constitución democrática, es decir, en la ilicitud de expectativas antidemocráticas al nivel del output, esto es, en la imposibilidad de que se conviertan en norma constitucional, cerrando así su apertura, pero sin embargo, sí permitan introducirse en el seno del ordenamiento. Cuando

de la Constitución. Sin embargo, posiblemente la interrelación que expresa dicho principio entre los conceptos de neutralidad y de indiferencia no sea del todo adecuada para expresar la dogmática del principio democrático contenida en el título x de la Constitución, en la medida en que la extraordinaria rigidez del procedimiento dispuesto para su reforma no resulta compatible con la indiferencia frente a las expectativas constitucionalizables. Por ello, en la Constitución española de 1978, resulta más coherente concebir al principio de neutralidad como principio de relatividad, con el que se expresa el carácter temporalmente relativo de la validez y de la eficacia de las disposiciones constitucionales. Sobre la concepción del principio de neutralidad como principio de relatividad, véase E. Bulla, "Die Lehre von der Streitbaren Demokratie. Versuch einer kritischen Analyse unter besonderer Berücksichtigung der Rechtsprechung der Bundesverfassungsgerichts", Op. cit., p. 341 y J. Becker, "Die Wehrhafte Demokratie des Grundgesetzes", en J. Isensee y P. Kirchhof (Edits.), Handbuch des Staatsrechts, Vol. v1l -Normativität und Schutz der Verfassung, Ed. C. F. Müller, Heidelberg, 1992, p. 312.

${ }^{57}$ Sin embargo, frente a ello podría afirmarse que una Constitución es tanto más eficaz cuando ésta más se garantice en el tiempo. Véase al respecto F. Bastida Freijedo, "La soberanía borrosa: la democracia", Fundamentos, Cuadernos monográficos de Teoría del Estado, Derecho Público e Historia Constitucional, No. 1, 1998, pp. 454 y 455. Por ello, se maximiza la pretensión teórica de una Constitución de ser eficaz; es allí donde, como ha quedado dicho, posibilitando el cambio democrático de sus normas, se prohíba la supresión del principio democrático, esto es, la posibilidad de un cambio antidemocrático. 
esto es así procede a la plasmación normativa de lo que se ha denominado doctrinalmente principio de no identificación..$^{58}$ De conformidad con este principio, incluso los enemigos de la democracia encuentran un ámbito en el cual puedan expresarse lícitamente en el seno del ordenamiento, aunque sus expectativas antidemocráticas no puedan ser objeto de decisión en el seno del procedimento democrático. En definitiva, lo que parece más compatible dogmáticamente con la función normativa de una Constitución democrática es cerrar las expectativas antidemocráticas a nivel del output, pero no del input.

Esto último sucede inevitablemente en el contexto de la defensa de la Constitución, como resultado de su contenido universal..$^{59}$ En efecto, como se tuvo la ocasión de poner de manifiesto con anterioridad, las doctrinas materiales clásicas negaron la posibilidad dogmática de que las normas jurídico-positivas pudieran servir de base para la supresión del orden axiológico subyacente al texto constitucional, de aquello que consideraban la verdadera Constitución del Estado. ${ }^{60}$ Pues bien, ha sido sobre la base de este presupuesto que no sólo afirmaron que en base al poder de reforma de la Constitución pudiese modificarse la Constitución metapositiva, como también, y en lo que aquí interesa, que los derechos fundamentales pudiesen servir para menoscabar la eficacia de aquélla. ${ }^{61}$ Es de esta manera que se construye la norma metapositiva de defensa de la Constitución. Pues bien, si se tiene en cuenta que seguramente lo más compatible con la función de la Constitución democrática sea el principio de no identificación,

\footnotetext{
${ }^{58}$ Véase E.-W. Böckenförde, “Das Recht der Gewissenfreiheit”, en Idem., Staat, Verfassung, Demokratie, Ed. Suhrkamp, Francfort, 1991, p. 226.

${ }^{59}$ Este contenido universal, consustancial a la defensa de la Constitución, es lo que precisamente permite explicar por qué la doctrina material ha entendido que las concretas disposiciones del texto constitucional en las que se pretende dotar de eficacia a la Constitución metapositiva se conciben sólo como algunas de las posibles reglas en las que se concreta aquel principio universal de defensa de la Constitución. Esto se ha puesto de manifiesto contemporáneamente con la construcción de la democracia militante, que ha entendido que las normas de lealtad que aparecen plasmadas en el texto de la Ley Fundamental de Bonn como un límite a determinados derechos fundamentales reconocidos en aquél son sólo algunas de las reglas en las que se concreta el principio metapositivo universal de democracia militante. Véase con carácter general BVerfGE 13, 46 (50) y E. Bulla, "Die Lehre der Streitbaren Demokratie", $0 p$. cit., p. 360.

${ }^{60}$ Véase C. Schmitt, Verfassungslehre, Op. cit., p. 22.

${ }^{61}$ Véase C. Schmitt, Ibid., pp. 27ss, Der Hüter der Verfassung, Ed. Duncker \&t Humblot, Berlin, 1985, pp. 126ss y 158-159, también en Die Diktatur, von den Anfängen des modernen Souveranitätsgedankens bis zum proletarischen Klassenkampf, Ed. Duncker \& Humblot, Berlin, 1978, pp. 242ss. También en parecido sentido véase "Reichstagsauflösungen", en Idem., Verfassungsrechtliche Aufsätze. Aufsätze aus den Jahren 1924-1954. Materialen zu einer Verfassungslehre, $3^{\text {a }}$ edición, Ed. Duncker \& Humblot, Berlin, 1985, p. 21 y "Weiterentwicklug des totales Staates in Deutschland", en Idem., Verfassungsrechtliche Aufsätze, Op. cit., pp. 362-363 y Der Hüter der Verfassung, Op. cit., p. 366ss.
} 
permitiendo que todas las expectativas puedan al menos expresarse en el seno del procedimiento democrático, parece claro que la categoría de la defensa de la Constitución no puede considerarse totalmente adecuada para tutelar su función.

En realidad, sólo si la tutela de la Constitución se plantea de conformidad con las exigencias de la defensa del Estado y sobre los presupuestos jurídico-positivos sobre los que se sustenta, cabe renunciar a declarar ilícitas las expectativas antidemocráticas que traten de insertarse en el seno del procedimiento democrático. ${ }^{62}$ Dicho de otro modo, el principio de no identificación sólo resulta viable en los términos de la defensa del Estado, no de la defensa de la Constitución. Por ello, y en definitiva, el modelo de defensa del Estado sirve mejor a la tutela de la función de la Constitución democrática que el sistema garantista de la defensa de la Constitución.

62 De esta manera, el contenido necesariamente universal de la defensa de la Constitución es sólo contingente en el ámbito de la defensa del Estado. 